\title{
A Clinico-Aetiological Study of Prolonged Fever at a Tertiary Care Centre in Patna, Bihar
}

\author{
Arshad Ahamad ${ }^{1}$, Praveen Kumar², Kalpana Chandra3 ${ }^{3}$ Amit Kumar Mishra ${ }^{4}$, \\ Manoj Kumar Choudhary ${ }^{5}$, Sudhir Kumar', Shailesh Kumar', Umakant Prasad ${ }^{8}$ \\ 1, 2, 4, 5, 6 Department of General Medicine, Indira Gandhi Institute of Medical Sciences (IGIMS), Patna, Bihar, \\ India. ${ }^{3}$ Department of Pathology, Indira Gandhi Institute of Medical Sciences (IGIMS), Patna, Bihar, India. \\ 7 Department of Microbiology, Indira Gandhi Institute of Medical Sciences (IGIMS), Patna, Bihar, India. \\ ${ }^{8}$ Department of Radiology, Indira Gandhi Institute of Medical Sciences (IGIMS), Patna, Bihar, India.
}

\section{ABSTRACT}

\section{BACKGROUND}

Prolonged fever can be defined as fever of more than 14 days duration. It can be caused by infection, non-infectious inflammatory diseases, malignancy, miscellaneous causes and undiagnosed causes. The present study was undertaken to study the clinical profile as well as aetiology of prolonged fever.

\section{METHODS}

A cross sectional study was conducted among patients of prolonged fever admitted in general medicine ward at IGIMS, Patna, Bihar. Patients were selected as per inclusion and exclusion criteria. A detailed history was taken followed by physical examination, systemic examination and investigations to find out the underlying aetiology.

\section{RESULTS}

Male patients were more than females. Most commonly affected age group was of 21 to 30 years comprising 25 patients followed by 13 patients in less than 20 years age group, 11 patients in $41-50$ years age group, 10 patients in $51-60$ years age group, 8 patients in $31-40$ years age group, 7 patients in $61-70$ years age group and 6 patients in $>70$ years age group. Maximum patients were in post monsoon season comprising 35 patients followed by 18 patients in summer, 17 patients in rainy and 10 patients in winters. Patients most commonly presented within 2 to 4 weeks of fever comprising 39 patients. All patients were having fever. Other symptoms present were cough / dyspnoea in 24 patients, weakness / body ache in 15 patients, abdominal pain in 14 patients, headache / irritability in 11 patients, arthralgia in 9 patients and altered sensorium in 2 patients. Most common aetiological diagnosis was tuberculosis in 32 patients followed by connective tissue disease (CTD) in 9 patients, liver abscess in 8 patients and haematological malignancy in 7 patients.

\section{CONCLUSIONS}

Prolonged fever is a common but difficult medical problem commonly caused by infection predominantly tuberculosis.

\section{KEY WORDS}

Pyrexia, PUO, Prolonged Fever
Corresponding Author: Dr. Praveen Kumar, Kailash-501, Jalalpur Heights, Mansarovar Colony, RPS More, Danapur, Patna - 801503, Bihar, India.

E-mail: praveen_kmr_23@yahoo.co.in

DOI: $10.14260 / j e m d s / 2021 / 128$

How to Cite This Article:

Ahamad A, Kumar P, Chandra K, et al. A clinico-aetiological study of prolonged fever at a tertiary care centre in Patna, Bihar. J Evolution Med Dent Sci 2021;10(09):595-599, DOI: 10.14260/jemds/2021/128

Submission 19-10-2020,

Peer Review 31-12-2020,

Acceptance 07-01-2021,

Published 01-03-2021.

Copyright (c) 2021 JEMDS. This is an open access article distributed under Creative Commons Attribution License [Attribution 4.0 International (CC BY 4.0)] 


\section{BACKGROUND}

Fever is an elevation of body temperature that exceeds the normal daily variation and occurs in conjunction with an increase in the hypothalamic set point. ${ }^{1}$ The average normal oral body temperature taken in midmorning is $36.7-37.4$ degree centigrade. ${ }^{2}$ Increase in hypothalamic set point is caused by release of various cytokines such as interleukin 1 , interleukin-6, tumour necrosis factor and ciliary neurotropic factor. ${ }^{1}$

Fever can be divided into two types based on duration. Acute fever is defined as fever of less than 14 days duration. Commonly acute febrile illness is self-limiting and readily diagnosed. Prolonged fever can be defined as fever of more than 14 days duration. It is a clinical condition which neither resolves spontaneously nor diagnosed by initial investigation. These patients develop distinguishing characteristics which may lead to diagnosis.

Practically, all the patients with prolonged fever at initial evaluation are of pyrexia of unknown origin (PUO) until associated with likely definitive diagnosis. PUO is a type of prolonged fever without an established aetiology despite intensive protocolised evaluation and diagnostic testing. It was originally defined by Petersdorf and Beeson in 1961. They defined PUO as an illness of more than three week's duration with fever of $38.3^{\circ} \mathrm{C}\left(101^{\circ} \mathrm{F}\right)$ on two occasions and no diagnosis could be made despite one week of inpatient evaluation. Later PUO was redefined in 1991 by Durack and Street with two major changes to the original definitions. They recommended four classes of PUO which were classical PUO as originally defined by Petersdorf and Beeson, nosocomial PUO, neutropenic PUO and human immunodeficiency virus (HIV) associated PUO. They also proposed a minimum three outpatient visits / three days of hospitalisation for minimum diagnostic evaluation before labelling the case as PUO. These are quantitative criteria of PUO which defied diagnosis after a reasonable workup of one-week duration. But considering the differential diagnostic facility available in different areas, PUO cannot be compared among different geographic areas. For optimal comparison of patient with PUO in different geographic area it has been proposed that quantitative criteria (diagnosis uncertain after one week of evaluation) be changed to qualitative criteria that require a performance of specific tests of investigations. As per this criteria PUO can be defined as when temperature is more $101^{\circ} \mathrm{F}$ on at least two occasions, illness duration more than 3 weeks, diagnosis that remain uncertain after a thorough history taking, physical examination and obligatory investigations such as complete blood count (CBC), erythrocyte sedimentation rate (ESR), C reactive protein (CRP), kidney function test (KFT), liver function test (LFT), lactate dehydrogenase, creatinine phosphokinase (CPK), ferritin, antinuclear antibody (ANA), RA factor, protein electrophoresis, blood culture, urine culture and tuberculin test. As per this criterion, currently or recently immune compromised patients are excluded from PUO. ${ }^{3}$

Prolonged fever can be caused by infection, non-infectious inflammatory diseases, malignancy, miscellaneous causes and undiagnosed causes. In resource poor country PUO is more frequent due to infection as compared to Western country where inflammatory and malignant disorder accounts for most of the cases. ${ }^{4}$ The present study was undertaken to study the clinical profile as well as aetiology of prolonged fever.

\section{METHODS}

A cross sectional study was conducted on patients of prolonged fever admitted in general medicine ward IGIMS, Patna, Bihar. The study was conducted for one year i.e. from August 2018 to September 2019. The patients were selected as per the following inclusion and exclusion criteria.

\section{Inclusion Criteria}

All new patients aged above 14 years with prolonged fever (i.e. temperature more than 101-degree Fahrenheit for at least two occasions) of more than 14 days without any diagnosis.

\section{Exclusion Criteria}

Patients not giving consent for study or not willing for protocolised investigation.

After selecting the patients as per inclusion and exclusion criteria, informed consent was obtained. A detailed history was taken including the history of travel, risk of venereal diseases, hobbies, drug abuse, and contact with animals. After history, general and systemic examination was performed which was repeated on daily basis to look for any evidence of underlying aetiological cause of fever. Temperature chart was maintained to look for pattern of the fever. After history and examination patients were investigated for aetiological diagnosis.

\section{Statistical Analysis}

Descriptive statistics was obtained from data collected from history, examinations and laboratory investigations. Number and percentage were enumerated for all categorical variables such as clinical findings and laboratory investigations.

\begin{tabular}{|cccc|}
\hline \multicolumn{5}{|c|}{ RESULT S } \\
\begin{tabular}{|cccc|}
\hline \multicolumn{5}{|c|}{ NI. No. } & Age Range & Number & Frequency in Percentage \\
1 & $<20$ & 13 & 16.25 \\
2 & $21-30$ & 25 & 31.25 \\
3 & $31-40$ & 8 & 10 \\
4 & $41-50$ & 11 & 13.75 \\
5 & $51-60$ & 10 & 12.5 \\
6 & $61-70$ & 7 & 8.75 \\
7 & $>70$ & 6 & 7.5 \\
\hline \multicolumn{3}{c}{ Table 1. Age Distribution } \\
\hline
\end{tabular}
\end{tabular}

\begin{tabular}{|cccc|}
\hline Sl. No. & Season & Number & $\begin{array}{c}\text { Frequency in } \\
\text { Percentage }\end{array}$ \\
1 & Winter (December - February) & 10 & 12.5 \\
2 & Summer (March - May) & 18 & 22.5 \\
3 & Rainy (June - August) & 17 & 21.25 \\
4 & Autumn / post monsoon & 35 & 43.75 \\
\hline \multicolumn{4}{|c|}{ (September - November) } \\
\hline
\end{tabular}

- $\quad$ Age distribution - Most common age group was 21 - 30 years followed by less than 20 years.

- Sex distribution - Out of 80 patients, 51 were males and 29 were females. 
- Seasonal distribution - Maximum patients (35) were in post monsoon season.

- Duration of fever - Patients most commonly presented within 2 to 4 weeks of fever comprised 39 patients.

\begin{tabular}{|cccc|}
\hline Sl. No. & Time Interval & Number & $\begin{array}{c}\text { Frequency in } \\
\text { Percentage }\end{array}$ \\
\hline 1 & 2 - 4 weeks & 39 & 48.75 \\
2 & $4-6$ weeks & 7 & 8.75 \\
3 & 6 - 8 weeks & 22 & 27.5 \\
4 & $>8$ & 12 & 15 \\
\hline \multicolumn{4}{c}{ Table 3. Duration of Fever } \\
\hline
\end{tabular}

- $\quad$ Symptom - Fever was present in all patients followed by cough / dyspnoea, weakness / body ache, abdominal pain, headache / irritability, arthralgia and altered sensorium.

\begin{tabular}{|c|c|c|c|}
\hline Sl. No. & Symptom / Signs & Number & $\begin{array}{c}\text { Frequency in } \\
\text { Percentage }\end{array}$ \\
\hline 1 & Fever & 80 & 100 \\
\hline 2 & Cough / dyspnoea & 24 & 30 \\
\hline 3 & $\begin{array}{c}\text { Weakness / body } \\
\text { ache }\end{array}$ & 15 & 18.75 \\
\hline 4 & Abdominal pain & 14 & 17.5 \\
\hline 5 & $\begin{array}{l}\text { Headache / } \\
\text { irritability }\end{array}$ & 11 & 13.75 \\
\hline 6 & Arthralgia & 9 & 11.25 \\
\hline 7 & Altered sensorium & 2 & 2.5 \\
\hline 8 & Hepatomegaly & 4 & 5 \\
\hline 9 & Splenomegaly & 10 & 12.5 \\
\hline 10 & Lymphadenopathy & 4 & 5 \\
\hline 11 & Rash & 1 & 1.25 \\
\hline \multicolumn{4}{|c|}{ Table 4. Symptoms and Signs } \\
\hline
\end{tabular}

\begin{tabular}{|c|c|c|c|}
\hline SI. No. & Diagnosis & Number & $\begin{array}{c}\text { Frequency in } \\
\text { Percentage }\end{array}$ \\
\hline \multirow{7}{*}{1} & Tuberculosis & Total - 32 & 39.82 \\
\hline & Pulmonary / pleural & 14 & 17.5 \\
\hline & Lymphadenitis & 4 & 5 \\
\hline & Ascites & 4 & 5 \\
\hline & Meningitis & 5 & 6.25 \\
\hline & Disseminated & 4 & 5 \\
\hline & Pericardial effusion & 1 & 1.25 \\
\hline 2 & Liver abscess & 8 & 10 \\
\hline 3 & Enteric fever & 4 & 5 \\
\hline \multirow{4}{*}{4} & Haematological malignancy & 7 & 8.75 \\
\hline & Leukemia & 4 & 5 \\
\hline & Lymphoma & 2 & 2.5 \\
\hline & Chronic myeloid leukaemia (CML) & 1 & 1.25 \\
\hline 5 & Urinary tract infection (UTI) & 4 & 5 \\
\hline \multirow{6}{*}{6} & $\begin{array}{c}\text { CTD } \\
\text { Systemic lupus erythematosus (SLE) }\end{array}$ & Total 9 & 11.25 \\
\hline & $\begin{array}{l}\text { Systemic lupus erythematosus (SLE) } \\
\text { Mixed connective tissue disorder }\end{array}$ & 3 & 3.75 \\
\hline & (MCTD) & 2 & 2.5 \\
\hline & Vasculitis & 2 & 2.5 \\
\hline & Stills disease & 1 & 1.25 \\
\hline & Seronegative polyarthritis & 1 & 1.25 \\
\hline 7 & Kala azar & 1 & 1.25 \\
\hline 8 & Malaria & 2 & 2.5 \\
\hline 9 & Leprosy with lepra reaction & 1 & 1.25 \\
\hline 10 & HIV with secondary infection & 2 & 2.5 \\
\hline 11 & $\begin{array}{l}\text { Lower respiratory tract infection } \\
\text { (LRTI) }\end{array}$ & 1 & 1.25 \\
\hline 12 & Diabetic foot & 1 & 1.25 \\
\hline 13 & Pyothorax & 1 & 1.25 \\
\hline 14 & Undiagnosed & 7 & 8.75 \\
\hline \multicolumn{4}{|c|}{ Table 5. Aetiology } \\
\hline
\end{tabular}

- Comorbidity - Most common comorbidity was diabetes mellitus (DM) in 9 followed by hypertension (HT) in 3, HIV positivity in 2, chronic liver disease (CLD) in 1 and hypothyroidism in 1 .

- Investigation - Most common laboratory abnormality was anaemia in 59 patients followed by leucocytosis in 18 , leukopenia in 5 and altered LFT in 5 patients. Out of 59 patients of anaemia 27 were having mild anaemia, 23 were having moderate anaemia and 9 patients were having severe anaemia.

- Diagnosis - Most common aetiological diagnosis was tuberculosis in 32 patients followed by connective tissue disease (CTD) in 9 patients, liver abscess in 8 patients and haematological malignancy in 7 patients.

\section{DISCUSSION}

Prolonged fever always poses challenges to clinicians despite availability of modern diagnostic tools. The disease spectrum has changed significantly in today's era with modern management guidelines but in many underdeveloped countries and even in India infectious pathology, tuberculosis in particular is the most prevalent aetiological disease. Many epidemiological studies conducted across the world has shown significant decline in infectious aetiology and increasing trends in connective tissue disorders and malignancy in the Western countries.

In our study of 80 patients, results analysis revealed that males outnumbered females (51 male and 29 female). Similar observation was made by other investigators but C Nandini et al., Md Shameem Haider and Lamiaa $S$ et al. found more females than males in their study. $5,6,7$

The most commonly affected age group was $21-30$ years comprising $31.25 \%$ patients followed by $16.25 \%$ in less than 20 years age group, $13.75 \%$ in 41 - 50 years age group, $12.5 \%$ in 51 - 60 years age group, $10 \%$ in $31-40$ years age group, $8.75 \%$ in $61-70$ years age group and $7.5 \%$ in $>70$ years age group. We had maximum patients in post monsoon season comprising $43.75 \%$ followed by $22.5 \%$ in summer, $21.25 \%$ in rainy and $12.5 \%$ patients in winter. Our patients most commonly presented within 2 to 4 weeks of fever comprising $48.75 \%$ patients followed by $27.5 \%$ between 6 - 8 weeks, 15 $\%$ after more than 8 weeks and $8.75 \%$ between $4-6$ weeks. D Kejriwal et al. conducted a study on 100 patients of pyrexia of unknown origin. The mean age of the patients was 32.4 years (range 12 - 65 years) and mean duration of fever before admission to the hospital was 85.3 days. ${ }^{8}$

Tanveer Mir et al. conducted a study to evaluate the aetiology of fever of unknown origin (FUO) at SKIMS, Srinagar on 91 cases with age ranging from 16 to 80 years. The mean duration of fever before hospitalisation was $26 \pm 4$ days. ${ }^{9} \mathrm{C}$ Nandini et al. conducted a study on 110 patients in a rural population in a tertiary care hospital of West Bengal. In their study, age of the patients varied from 15 years to 78 years with a mean age being $33.68 \pm 18.77$. The maximum number of patients belonged to the age group of $1-20$ yrs. (43.63\%) followed by $21-40$ (23.63\%) years leading to maximum concentration of patients less than 40 years amounting to 65.5 $\% .{ }^{5}$ We also observed $57.50 \%$ patients in less than 40 years of age group. Lamiaa $S$ et al. in their study observed mean age of 45.02 and most cases were in the age group of $21-40$ years. ${ }^{7}$

In our study, fever was observed in all patients followed by cough / dyspnoea in $30 \%$, weakness / body ache in $18.75 \%$, abdominal pain in $17.5 \%$, headache / irritability in $13.75 \%$, arthralgia in $11.25 \%$ and altered sensorium in $2.5 \%$ patients. $12.5 \%$ patients were having splenomegaly, $5 \%$ patients were having hepatomegaly and $5 \%$ patients were having lymphadenopathy and $1.25 \%$ patients were having rash. We 
observed DM in $11.25 \%$ patients, followed by HT in $3.75 \%$, HIV positivity in $2.5 \%$, CLD in $1.25 \%$ and hypothyroidism in $1.25 \%$. We found most common laboratory abnormality was anaemia in $73.75 \%$ patients followed by leucocytosis in 22.5 $\%$, leucopoenia in $6.25 \%$ and altered LFT in $6.25 \%$. However, in the study done by Tanveer Mir et al. they observed pallor, lymphadenopathy and splenomegaly commonly in patients with FUO due to malignancy. They found abnormal liver function in all groups with deranged kidney functions tests predominantly in collagen vascular disease group. ${ }^{9}$ Lamiaa $S$ et al. noticed anaemia in $50 \%$ patients, leukocytosis $31.12 \%$ patients, leucopenia in $13.33 \%$ patients abnormal LFT in 11.1 $\%$ patients, abnormal kidney function test in $5.6 \%$ patients and $16.7 \%$ patients had coagulopathy. ${ }^{7}$ Md Shameem Haider observed persistent fever and generalised weakness in all patients followed by arthralgia / arthritis in $51.3 \%$ cases. $^{6}$ On evaluation of laboratory profile, they also found $\mathrm{Hb} \%$ (gm / dl) within normal range in most of the patients which was not concordant with our observation where we found anaemia in $73.75 \%$ patients ranging from mild to severe. Leucopenia was detected in $56.9 \%$ of patients which was significantly higher than our finding.

In our study, the most common cause for prolonged fever was infection accounts for $66.25 \%$ cases followed by connective tissue disorder in $11.25 \%$. Malignancy and undiagnosed comprises $8.75 \%$ each. Despite awareness about tuberculosis since yester years and National Tuberculosis Programme run by Government of India, tuberculosis outnumbered (39.28\%) as underlying aetiology which is comparable with studies done by another investigator in India. In the study conducted by D Kejriwal et al. infection was the commonest cause, being responsible for $53 \%$ of cases of PUO. Out of which tuberculosis was the single most common infection followed by haematological malignancies in 13 patients. Systemic lupus erythematosus was responsible in five cases. In 14 patients, diagnosis could not be made. In their studies other infectious causes were comparable with our findings like abscesses in 7 patients, enteric fever in 5 patients, UTI in 4 patients, kala-azar in 5 patients and malaria in 3 patients. ${ }^{8} \mathrm{C}$ Nandini et al. Observed infections in $69 \%$, out of which Tuberculosis was the leading cause in $44 \%$ of cases followed by chronic UTI ( $8.2 \%)$, enteric fever (5.5\%) and malaria (4.5\%). They also found various malignancies in 12.7 $\%$ of patients and inflammatory disorders in $10.9 \%$. No diagnosis could be reached in $3.6 \%$ cases. ${ }^{5}$ Shameem Haider observed tuberculosis specially at extra pulmonary sites as most common cause followed by malignant aetiology. ${ }^{6} \mathrm{We}$ also found extra pulmonary tuberculosis to be more prevalent in our study. Tanveer Mir et al. were able to make aetiological diagnosis in $66 \%$ of cases. In their studies infectious diseases (44\%) was the leading cause of FUO followed by collagen vascular diseases and malignancies (12\% each). Amongst the infection group, brucellosis and salmonellosis comprised the majority of cases (25\% each) not tuberculosis as observed in other studies from India and in our analysis also. ${ }^{9}$

Lamiaa S et al. on study of 90 patients, 68 (75.6\%) were diagnosed, whereas 22 (24.4\%) were discharged without definite diagnosis. Among 68 (75.6\%) patients who were diagnosed, infection was the most common aetiology in 46 (51.1\%), where bacterial infection was seen in 45 (50\%), malignancy was detected in 15 (16.7\%).Connective tissue diseases were demonstrated in six (6.6\%). Among the infectious causes, salmonellosis was reported in 14 (15.6\%) patients. ${ }^{7}$ This variation in prevalence of infectious disease other than tuberculosis among the population might be because of multiple factors like education, living condition, hygiene, sociocultural practices and vaccination and so on.

Study conducted by Thierry Zenone observed noninfectious inflammatory disorders representing the most prevalent category (35.5\%), surpassing infections (30.8\%). Giant cell arteritis and polymyalgia rheumatica were particularly frequent in the elderly. ${ }^{10}$ In our study also CTD was second most common cause of prolonged fever.

\section{CONCLUSIONS}

Prolonged fever is a common but difficult medical problem caused by infection, connective tissue disorder and malignancy. Infection predominantly tuberculosis is the most common cause in India suggesting ignorance, low socioeconomic status and less frequently available modern diagnostic modality to most of the patients. Undiagnosed prolonged fever is still significant, needing exhaustive investigation and research.

Data sharing statement provided by the authors is available with the full text of this article at jemds.com.

Financial or other competing interests: None.

Disclosure forms provided by the authors are available with the full text of this article at jemds.com.

\section{REFERENCES}

[1] Charles A, Dinarello, ReuvanPorat. Fever. In: Kasper, Fauci, Hauser, et al. eds. Harrison's Principles of Internal medicine. 19th edn. McGraw-Hill Education 2015: p. 1236.

[2] Nadler PL, Gonzales R. Fever and hyperthermia. In: Papadakis MA, McPhee SJ, eds. Current medical diagnosis and treatment. 57th edn. McGraw-Hill Education 2018: p. 34-5.

[3] Bleeker-Rovers CP, Van der Meer JWM. Fever of unknown origin. In: Kasper, Fauci, Hauser, et al. eds. Harrison's Principles of Internal medicine. 19th edn. McGraw-Hill Education 2015: p. 135-41.

[4] Vnaderschuren S, Knockaert D. Fever of unknown origin. 5th edn. Oxford University Press 2010: p. 423-31.

[5] Chatterjee N, Chakraborty S, Mukhopadhyay M, et al. A Cross - sectional study of undiagnosed fever in a rural population at a tertiary care hospital of West Bengal. Annals of International Medical and Dental Research 2018;4(3):7-10.

[6] Md. Shameem H. Clinio - pathological evaluation of fever of more than three weeks: a cross sectional study in a tertary care hospital. Chattagram Maa - 0 - Shishu Hospital Medical Collge Journal 2018;17(2):6-13.

[7] Sakr LS, Abdelrehim ASE, Mahran ZG. Evaluation of different patterns and etiologies of classic form of pyrexia of unknown origin in Assiut University fever unit. Journal of Current Medical Research and Practice 2019;4(1):98103. 
[8] Kejriwal D, Sarkar N, Chakraborty SK, et al. Pyrexia of unknown origin: a prospective study of 100 cases. Journal of Postgraduate Medicine 2001;47(2):104-7.

[9] Mir T, Dhobbi GN, Koul AN, et al. Clinical profile of classical fever of unknown origin (FUO). Caspian J Internal Med 2014;5(1):35-9.
[10] Zenone T. Fever of unknown origin in adults: evaluation of 144 cases in non - university hospital. Scandinavian Journal of Infectious Diseases 2006;38(8):632-8. 